\title{
Effects and Mechanisms of Chinese Herbal Medicine in Ameliorating Myocardial Ischemia-Reperfusion Injury
}

\author{
Qing Liu, ${ }^{1,2}$ Jiqiang Li, ${ }^{2}$ Jing Wang, ${ }^{2}$ Jianping Li, ${ }^{1}$ Joseph S. Janicki, ${ }^{1}$ and Daping Fan ${ }^{1}$ \\ ${ }^{1}$ Department of Cell Biology and Anatomy, University of South Carolina School of Medicine, Columbia, SC 29208, USA \\ ${ }^{2}$ The Second Clinical School of Medicine, Guangzhou University of Chinese Medicine, Guangzhou 510405, China \\ Correspondence should be addressed to Daping Fan; daping.fan@uscmed.sc.edu
}

Received 24 July 2013; Revised 26 August 2013; Accepted 4 September 2013

Academic Editor: Joen-Rong Sheu

Copyright (c) 2013 Qing Liu et al. This is an open access article distributed under the Creative Commons Attribution License, which permits unrestricted use, distribution, and reproduction in any medium, provided the original work is properly cited.

\begin{abstract}
Myocardial ischemia-reperfusion (MIR) injury is a major contributor to the morbidity and mortality associated with coronary artery disease, which accounts for approximately 450,000 deaths a year in the United States alone. Chinese herbal medicine, especially combined herbal formulations, has been widely used in traditional Chinese medicine for the treatment of myocardial infarction for hundreds of years. While the efficacy of Chinese herbal medicine is well documented, the underlying molecular mechanisms remain elusive. In this review, we highlight recent studies which are focused on elucidating the cellular and molecular mechanisms using extracted compounds, single herbs, or herbal formulations in experimental settings. These studies represent recent efforts to bridge the gap between the enigma of ancient Chinese herbal medicine and the concepts of modern cell and molecular biology in the treatment of myocardial infarction.
\end{abstract}

\section{Introduction}

Myocardial infarction (MI) and the accompanying acute loss of viable myocardium is the leading cause of death in industrialized countries. Even if the patient survives the acute phase of MI, the subsequent adverse myocardial remodeling and impairment of cardiac function severely impact their quality of life and 5-year survival. Early restoration of blood flow to the ischemic myocardium is a common treatment strategy aimed at limiting myocardial infarct size. However, reperfusion can cause additional cell death and, in many cases, paradoxically increase infarct size, a situation referred to as myocardial ischemia-reperfusion (MIR) injury. MIR is characterized by a rapid increase in cytokines and chemokines and an influx of leukocytes into the vulnerable region bordering the infarcted site. This inflammatory response not only results in cardiomyocyte apoptosis during the acute phase, but also results in an adverse myocardial remodeling that further compromises cardiac function. Therefore, limiting ischemia-reperfusion (I/R) induced myocardial inflammation may not only lower the acute death rate, but also improve long term survival and quality of life [1]. Chinese herbal medicine, especially combined herbal formulations, has been widely used in traditional Chinese medicine for the treatment of MI for hundreds of years. The purpose of this review is to highlight recent studies that experimentally address the mechanistic effects of extracted compounds, single herbs, or herbal formulations on several factors and pathways known to be involved in MIR injury.

\section{Myocardial Ischemia-Reperfusion Injury}

2.1. Oxidative Stress. Reactive oxygen species (ROS) have both a physiological and pathological role in cellular and tissue adaptation to environmental factors. Normally, low levels of oxygen radicals and oxidants are present in cells and are important in maintaining cellular homeostasis, mitosis, differentiation, and signaling [2]. However, during MIR, ROS formation is markedly increased and cellular injury occurs (Figure 1). Although mammalian cells express endogenous free radical scavenging enzymes, such as superoxide dismutase (SOD), catalase (CAT), and glutathione peroxidase $(\mathrm{GPx})$, these antioxidative defenses are insufficient during MIR $[3,4]$. Oxidative stress during MIR injury contributes to a vicious cycle as it promotes mitochondrial dysfunction, excitotoxicity, lipid peroxidation, and inflammation [5-7]. 


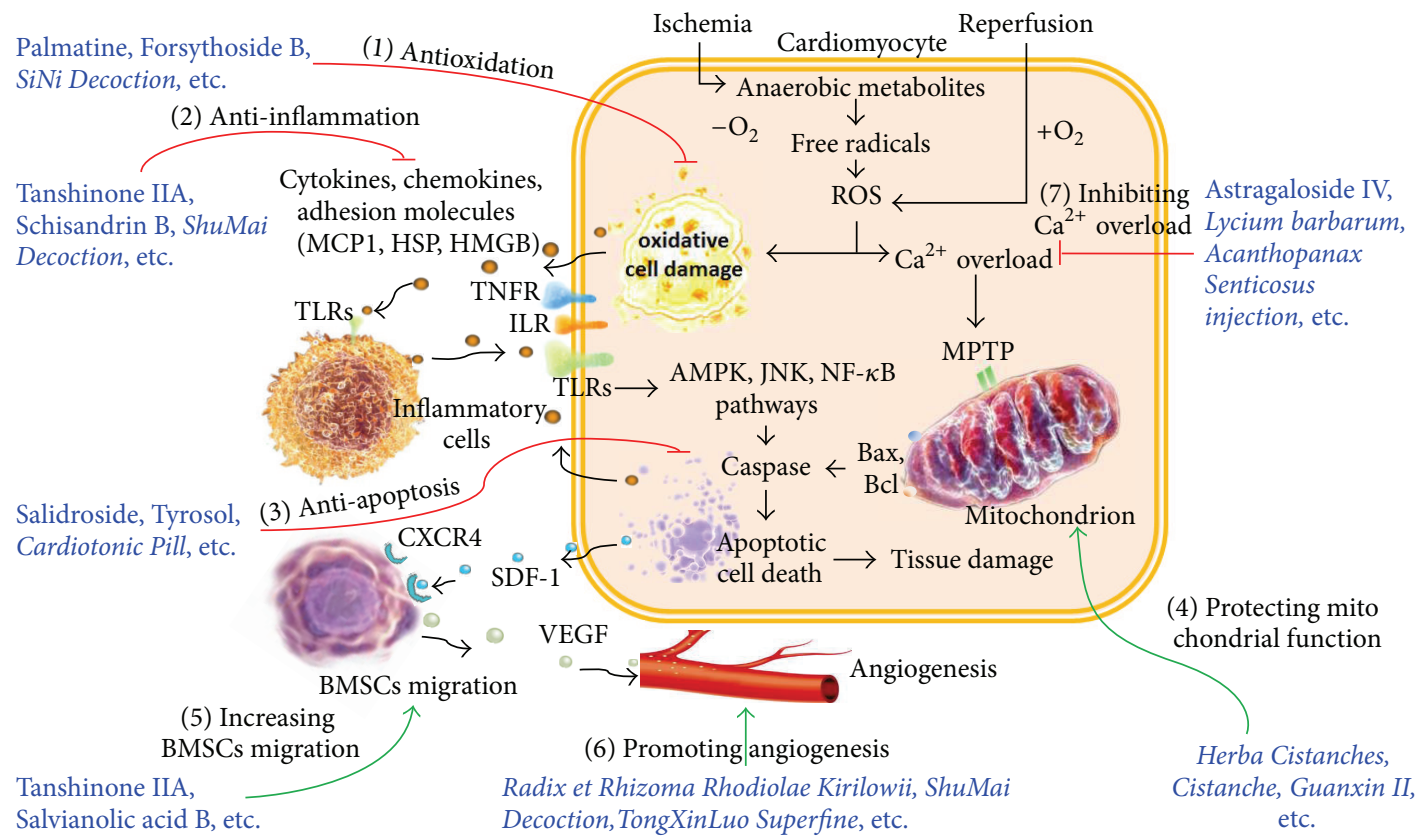

FIGURE 1: Effects and mechanisms of Chinese herbal medicine in myocardial ischemia-reperfusion (MIR) injury. During ischemia, oxygen is not available to accept the electrons in the metabolic degradation of substrates, and consequently anaerobic metabolites become important in the preservation of myocardial viability. However, free radicals and reactive oxygen species (ROS) formation is markedly increased in this procedure. Reperfusion also generates high ROS levels which have an adverse impact on specific signal transduction systems, thereby predisposing the heart to further oxidative cell damage. Damaged cell debris, fibrinogen, cytokines, and chemokines will activate the receptors, including TLRs, TNFR, and ILR, in the host inflammatory cells as well as the cardiomyocytes. This sterile inflammatory process leads to the formation of a vicious circle, whereby the cardiomyocyte TLRs, TNFR, and ILR are activated by inflammatory cell-generated ligands. Typically, this has an adverse impact on specific signal transduction systems (e.g., AMPK, JNK, and NF- $\kappa$ B pathways), thereby activating the caspase cascade. Elevated ROS levels also result in intracellular $\mathrm{Ca}^{2+}$ overload which adversely affects mitochondrial function by opening the mitochondrial permeability transition pore (MPTP). As a result, the balance between Bax and Bcl is interrupted and the caspase cascade is further activated, leading to apoptotic cell death and myocardial tissue damage. Injured tissue expresses SDF-1, which interacts with its specific receptors (e.g., CXCR4) to facilitate the trafficking, adhesion, and infiltration of bone marrow derived stem cells (BMSCs). BMSCs produce high levels of the endothelial cell-specific angiogenic factor, VEGF, which is a critical regulator of angiogenesis that includes the stimulation of proliferation, migration, and proteolytic activity of endothelial cells and eventually leads to an increase in vessel density and the facilitating of myocardial regeneration and remodeling. During the MIR injury process, there are seven target areas where Chinese herbal medicine can exert protective effects on cardiomyocyte. Examples are as follows: (1) anti-oxidation actions of Palmatine, Forsythoside B, and SiNi Decoction; (2) anti-inflammatory properties of Tanshinone IIA, Schisandrin B, and ShuMai Decoction; (3) anti-apoptosis ability of Salidroside, Tyrosol, and Cardiotonic Pill; (4) protection of mitochondrial function by Herba Cistanches, Cistanche, and Guanxin II; (5) increasing BMSCs migration by Tanshinone IIA and Salvianolic acid B (6) promoting angiogenesis by Radix et Rhizoma Rhodiolae Kirilowii, ShuMai Decoction and TongXinLuo Superfine; and (7) inhibiting $\mathrm{Ca}^{2+}$ overload by Astragaloside IV, Lycium barbarum, and Acanthopanax senticosus injection.

2.2. Sterile Inflammation. Ischemia and reperfusion cause sterile inflammation. Nevertheless, the consequences of MIR share many phenotypic parallels with activation of a host immune response directed toward invading microorganisms [8]. This sterile inflammation is mainly triggered by the interactions between toll-like receptors (TLRs) and their endogenous ligands generated in ischemic and reperfused myocardium, such as apoptotic cell debris, fibrinogen, high mobility group box (HMGB) 1, and heat shock proteins (HSPs) [9]. The activation of immune cell and cardiomyocyte TLR and other signaling pathways results in a vicious cycle of inflammatory response in the $I / R$ region and causes significant cardiomyocyte apoptosis (Figure 1). Following the acute I/R period, the cardiac function is further compromised by adverse myocardial remodeling [10]. The magnitude of the inflammation during the acute phase determines the extent to which cardiac function is compromised during the following myocardial remodeling phase.

During the sterile inflammation phase of MIR, TLRs play detrimental roles as demonstrated by extensive experimental evidence [11]. To date, 11 TLRs (TLR1-TLR11) have been identified in mammals. It should be noted that, during MIR, the expression of TLR4 is significantly increased in both the failing myocardium, and infiltrated macrophages and thus TLR4 is thought to be a central mediator of inflammation and cardiac injury. TLR4 has been identified as a mediator of inflammation and organ injury in several models of sterile tissue injury including MIR, and a soluble inhibitor of TLR4 was able to prevent contractile dysfunction in wildtype cells [12]. Using a temporary left anterior descending 
(LAD) artery occlusion model, Oyama et al. first observed myocardial infarct size reductions in 2 distinct strains of mice that lack functional TLR4 signaling, accompanied with reduced neutrophil infiltration in the affected myocardium [13]. TLR2, which is expressed in cardiomyocytes and many other cell types, also contributes to the pathogenesis of cardiac dysfunction during MIR $[14,15]$. Activation of TLR2, TLR4, and TLR5 increases the myocardial level of the inflammatory cytokines, chemokines, and cell surface adhesion molecules [16]. Given the known role of TLR4 and TLR2 in MIR, inhibition of TLR4 and TLR2 signaling is a promising approach to reduce morbidity and mortality in MI patients.

There are a variety of TLR ligands generated during MIR. For example, heat shock proteins (HSPs) are a class of molecular chaperones that promote intracellular protein folding. They may be released into the extracellular space after cell trauma and interact with adjacent cells or distant cells via bloodstream delivery [17]. Extracellular HSP60 induced apoptotosis via the activation of TLRs [18]. Another example is HMGB1 which is a damage-associated molecular pattern (DAMP) protein secreted by injured cells [19]. It plays a major role in early MIR by binding to TLRs and the receptor for advanced glycation end products (RAGE), resulting in the activation of proinflammatory pathways and enhanced myocardial injury [20]. In fact, a prerequisite for neutrophil-mediated tissue damage is the "priming" effect of various pro-inflammatory stimuli generated by damaged tissue during MIR, such as HSP60 and HMGB1 [21]. Cytokines released by TLR-activated cells such as tumor necrosis factor-alpha (TNF- $\alpha$ ) and IL-1 can elicit neutrophil polarization and upregulation of cell-surface glycoproteins such as macrophage adhesion molecule-1 (Mac-1) [22]; Mac1 upregulation in peripheral neutrophils is a very early event in MIR [23].

2.3. Apoptosis and Mitochondrial Function. MIR leads to the activation of cell death programs, including apoptosis, autophagy-associated cell death, and necrosis [24]. Apoptosis involves an orchestrated caspase signaling cascade, including caspase- 3 and caspase-9, which induces a self-contained program of cell death, characterized by the shrinkage of the cell and its nucleus, with plasma membrane integrity persisting until late in the process [25]. The balance between apoptotic factors $\mathrm{Bcl}-2$ and $\mathrm{Bax}$ has been found altered in cardiomyocytes during ischemia [26]. Autophagy is stimulated by nutrient starvation and growth factor deprivation when cells are unable to take up external nutrients. Autophagy is also activated by decreases in ATP in order for the cell to maintain energy homeostasis and survival. Autophagy may serve primarily to maintain energy production during acute ischemia but switch to clear up damaged organelles during chronic ischemia or reperfusion [27].

Multiple cell signaling pathways, such as the AMPK, JNK, and NF- $\kappa$ B pathways, have been shown to be involved in MIR-induced cardiomyocyte apoptosis (Figure 1). AMPK orchestrates the regulation of energy-generating and energyconsuming pathways; its activation has been shown to protect the heart against ischemic injury $[28,29]$. Activated JNK signaling, especially in mitochondria, is associated with oxidative stress, mitochondrial dysfunction, and cell death [30]; it is a key modulation event in cell death mediated by reactive oxygen and nitrogen species [31]. JNK is also required for TNF- $\alpha$-stimulated ROS production and cytochrome c-mediated cell death; Bcl-2 family members are essential components of this mitochondrial apoptotic machinery. Studies have suggested that blockage of JNK mitochondrial translocation or JNK inhibition prevents ROS production and mitochondrial dysfunction and may be an effective treatment for I/R-induced cardiomyocyte death [32-35]. The nuclear factor kappa B (NF- $\kappa \mathrm{B})$ also modulates apoptosis during ischemia and reperfusion [36]. TLR signaling pathway leads to translocation of NF- $\kappa \mathrm{B}$ to the nucleus and thus up-regulation of expression of proinflammatory cytokines. However, there is the possibility that a crosstalk between the TLR/NF- $\kappa \mathrm{B}$ and PI3K/Akt signaling pathways and modulation of the crosstalk could protect the myocardium from I/R injury [37].

Within the mitochondria dependent intrinsic apoptosis pathway, which has an important function in cardiac cell injury under various pathological conditions [38], mitochondrial permeability transition pore (MPTP) opening plays a pivotal role [39]. The event of MPTP opening is affected by various factors including intracellular $\mathrm{Ca}^{2+}$, oxidative radicals, ATP levels and the levels of Bcl-2 family proteins [40].

2.4. Bone Marrow Stem Cell Migration. Bone marrow mesenchymal stem cells (BMSCs) are multipotent cells that secrete angiogenic factors. Injured tissues express specific receptors, such as CXCR4, and/or their ligands including stromal cell-derived factor-1 (SDF-1), to facilitate trafficking, adhesion, and infiltration of BMSCs. During MIR, BMSCs are preferentially attracted to and retained in the ischemic tissue $[41,42]$. As a result of the hypoxic microenvironment, these BMSCs produce high levels of vascular endothelial growth factor (VEGF), leading to an increase in vessel density and facilitating myocardial regeneration and remodeling $[43,44]$ (Figure 1).

2.5. Angiogenesis. Angiogenesis refers to the sprouting, bridging, intussusception, and/or enlargement of capillaries. In the late stage of MI repair, enhancement of blood flow to ischemic myocardium can result from either true angiogenesis or the recruitment of preexisting coronary collaterals [45]. VEGF is an endothelial cell-specific angiogenic factor and also a critical regulator of angiogenesis that stimulates proliferation, migration, and proteolytic activity of endothelial cells [46]. Ischemia or coronary artery occlusion induces myocardial VEGF expression, which leads to an angiogenesis-induced restoration of tissue blood flow and the prevention of further tissue damage (Figure 1). In addition, VEGF is a potent survival factor during physiological and tumor angiogenesis, and has been shown to induce expression of anti-apoptotic proteins in endothelial cells [47, 48].

2.6. Other Factors. The activation of ATP-sensitive potassium (KATP) channel subunits and ATPase, and calcium $\left(\mathrm{Ca}^{2+}\right)$ 
overload are also involved in MIR (Figure 1). Ischemiareperfusion may activate some ion channels that do not open under normal physiological conditions. One such channel is the KATP channel, whose activation facilitates potassium ion efflux, hyperpolarization, and action potential repolarization. The resulting shortening of the action potential duration decreases the total influx of sodium and calcium, which alleviates overloading of intracellular calcium $\left(\mathrm{Ca}^{2+}\right)$ which in turn weakens myocardial contraction force and reduces myocardial oxygen consumption. Therefore, the opening of KATP channels plays an active role in protecting the heart against MIR injury.

\section{Effects and Mechanisms of Chinese Herbal Medicine in MIR}

The typical symptoms of cardiovascular diseases induced by MIR have been recorded in several ancient books of Traditional Chinese Medicine (TCM), such as Inner Canon of Huangdi and Treatise on Febrile Diseases. In TCM, Qi (energy) and Blood (material) are the main components compromised in MIR, whereby the principal mechanism is considered to be a disorder or deficiency of $Q i$ and a disorder of the circulation (blood stasis) that results in severe pain and even death. Therefore, the main aims of Chinese herbs and herbal formulations in MIR treatment are to regulate or replenish $Q i$, and to unblock circulation or resolve blood stasis. In Tables 1-4, we list four categories of Chinese herbal medicine that have been used in the practice of TCM and/or recent research, including compounds extracted from herbs (Table 1), single herbs (Table 2), decoctions (Table 3), and patent drugs made up of Chinese herbs (Table 4). All of the abbreviations used in these tables are listed at the end of the paper, and the main mechanisms and the representatives of Chinese herbal medicine in MIR treatment are schematized in Figure 1. In the following sections, these herbal medicines are grouped according to their efficacy in TCM terminology, and the underlying cellular and molecular mechanisms demonstrated by experimental investigations are discussed.

3.1. Anti-Oxidation. Many Chinese herbal medicines, including extracted compounds, single herbs, decoctions, and patent drugs, exert their beneficial effects on MIR via their anti-oxidative activity. A number of biomarkers have been used to evaluate the antioxidative effects of these Chinese herbal medicines, such as ROS, SOD, GPx, CAT, nitric oxide synthase (NOS), malondialdehyde (MDA), myeloperoxidase (MPO), heme oxygenase (HO)-1, superoxide anion, GOT, 15-F2t-isoprostane (15-F2t-IsoP), ET-1, cycloxygenase-2 (COX-2), thioredoxin-1 (Trx-1), thioredoxin-related protein-32 (TRP32), redox-sensitive PKC $\varepsilon / m K A T P$ pathway, glutathione (GSH), oxidized glutathione (GSSG), glutathione reductase (GRD), CuZnsuperoxide dismutase (CuZn-SOD), and Mn-SOD.

Through in vivo and in vitro experiments, Kim et al. revealed that palmatine, a compound extracted from the Chinese herb, Coptidis rhizome, markedly reduced serum MDA level, and the activity of SOD and CAT in the cardiac tissues, as well as the COX-2 and iNOS expressions in MIR myocardium of rats [49]. Jiang et al. reported that the MDA content and MPO activity in ischemic myocardial tissue of rats treated with Forsythoside B, a compound derived from the Chinese herb, Lamiophlomis rotate (Benth.) $K u d o$, were both significantly reduced. These reductions were accompanied by a significantly improved recovery in myocardial function [50]. Hwa et al. reported that 2Methoxycinnamaldehyde (2-MCA), a compound derived from the Chinese herb, Cinnamomum cassia, significantly increased HO-1 induction by promoting the translocation of Nrf-2 from cytosol to nucleus in endothelial cells in an MIR model [51]. In addition, $\mathrm{Hu}$ et al. demonstrated that cyclovirobuxine $\mathrm{D}$, a compound derived from the Chinese herb, Buxus microphylla, significantly protected rat aorta endothelial cells against hypoxia-induced injury and enhanced nitric oxide (NO) release from endothelial cells; these effects were inhibited by nitric oxide synthase (NOS) inhibitor N-nitroL'argininemethyl ester (L-NAME) [52]. Das et al. studied the effects of a single herb, Makhana, and demonstrated that the cardioprotective properties of Makhana were linked to its ability to scavenge ROS [53]. Some decoctions and patent drugs made up of Chinese herbs have also been shown to exert the anti-oxidative effects on MIR. Zhao et al. found that SiNi Decoction (SND), composed of Chinese herbs, Aconite, Ginger and Licorice, could enhance the activity of myocardial and myocyte mitochondrial SOD and reduce MDA by increasing the expression of Mn-SOD mRNA [54]. Wang et al. reported that in rats treated with Acanthopanax Senticosus Injection (ASI) at doses of 25,50 , and $100 \mathrm{mg} / \mathrm{kg}$ via femoral vein infusion $30 \mathrm{~min}$ after coronary occlusion, the content of myocardial MDA was decreased significantly and dose-dependently and the activities of myocardial SOD and GSH-Px were increased dramatically [55].

3.2. Anti-Inflammation. The manifestation of MIR shares many phenotypic similarities with the activation of a host immune response directed toward invading microorganisms. HSPs and HMGB1 are both involved in the initiation of host defense and tissue repair. Molecules derived from immune cells and cardiomyocytes have been utilized as biomarkers to evaluate the anti-inflammatory effects of Chinese herbal medicine on MIR, including IL-6, MCP-1, TGF- $\beta 1$, TNF- $\alpha$, CRP, IL-1 $\beta$, VCAM-1, ICAM-1, HMGB1, HSP25 and Hsp70, macrophage adhesion molecule-1 (Mac-1), troponinT (Tn-T), phosphorylated p38, activated MAPK, and tissue inhibitor of matrix metalloproteinase (TIMP)-1.

Ren et al. indicated that Tanshinone IIA (Tan IIA), a compound extracted from the Chinese herb, Salvia miltiorrhiza Bunge, attenuated expression of MCP-1, TGF- $\beta 1$, and TNF- $\alpha$ as well as macrophage infiltration in rats when administered intragastrically at a dose of $60 \mathrm{mg} / \mathrm{kg} /$ day [56]. Jiang et al. reported that treatment with Forsythoside B significantly decreased the levels of TNF- $\beta$, IL-6, and HMGB1 in a rat MIR model $[24,50]$. Results of a study by Chiu and Ko indicated that the reduction of Hsp25 and Hsp70 expression by Schisandrin B (Sch B), a compound extracted from Chinese herb, Schisandra chinensis, in MIR rats resulted 


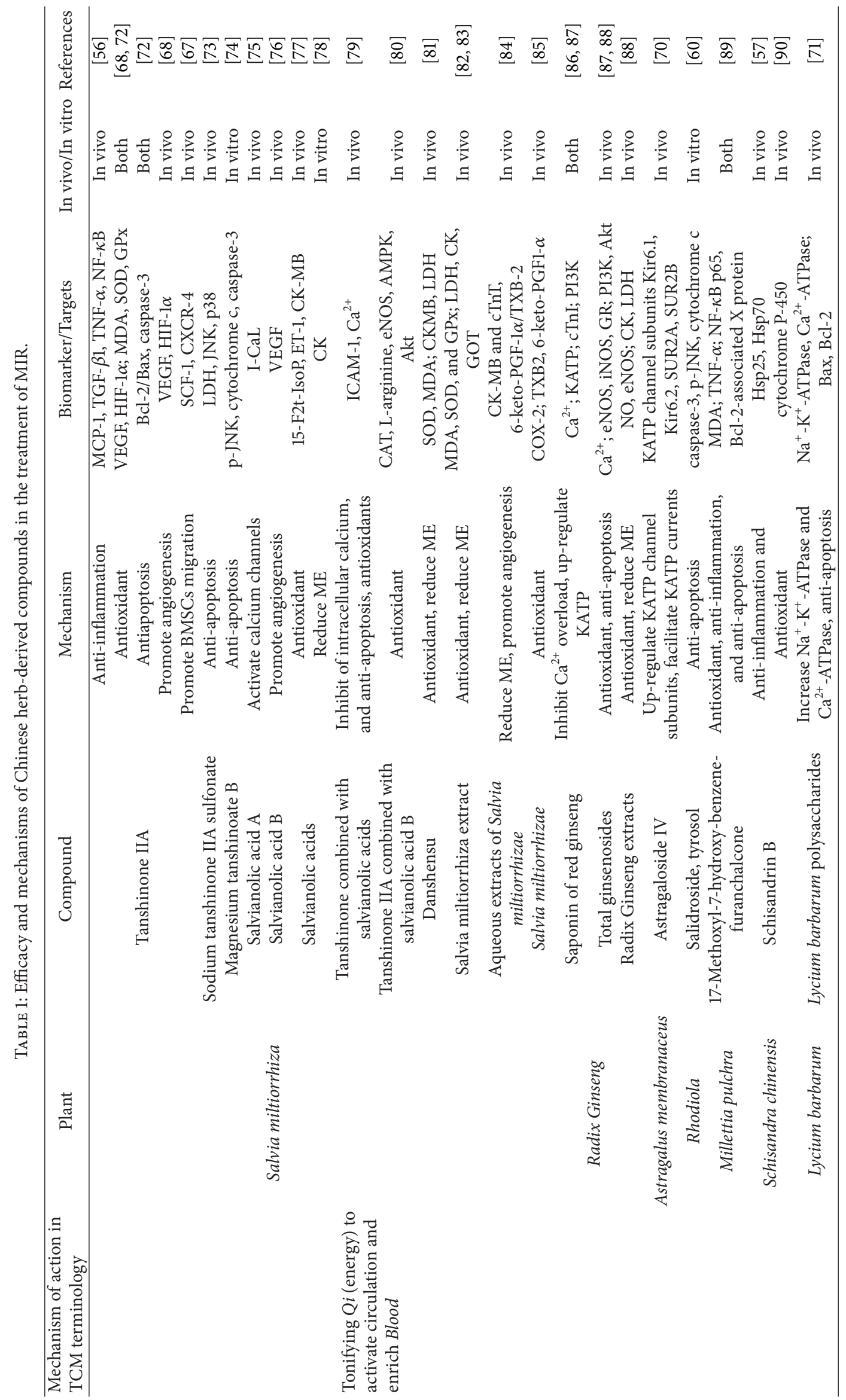




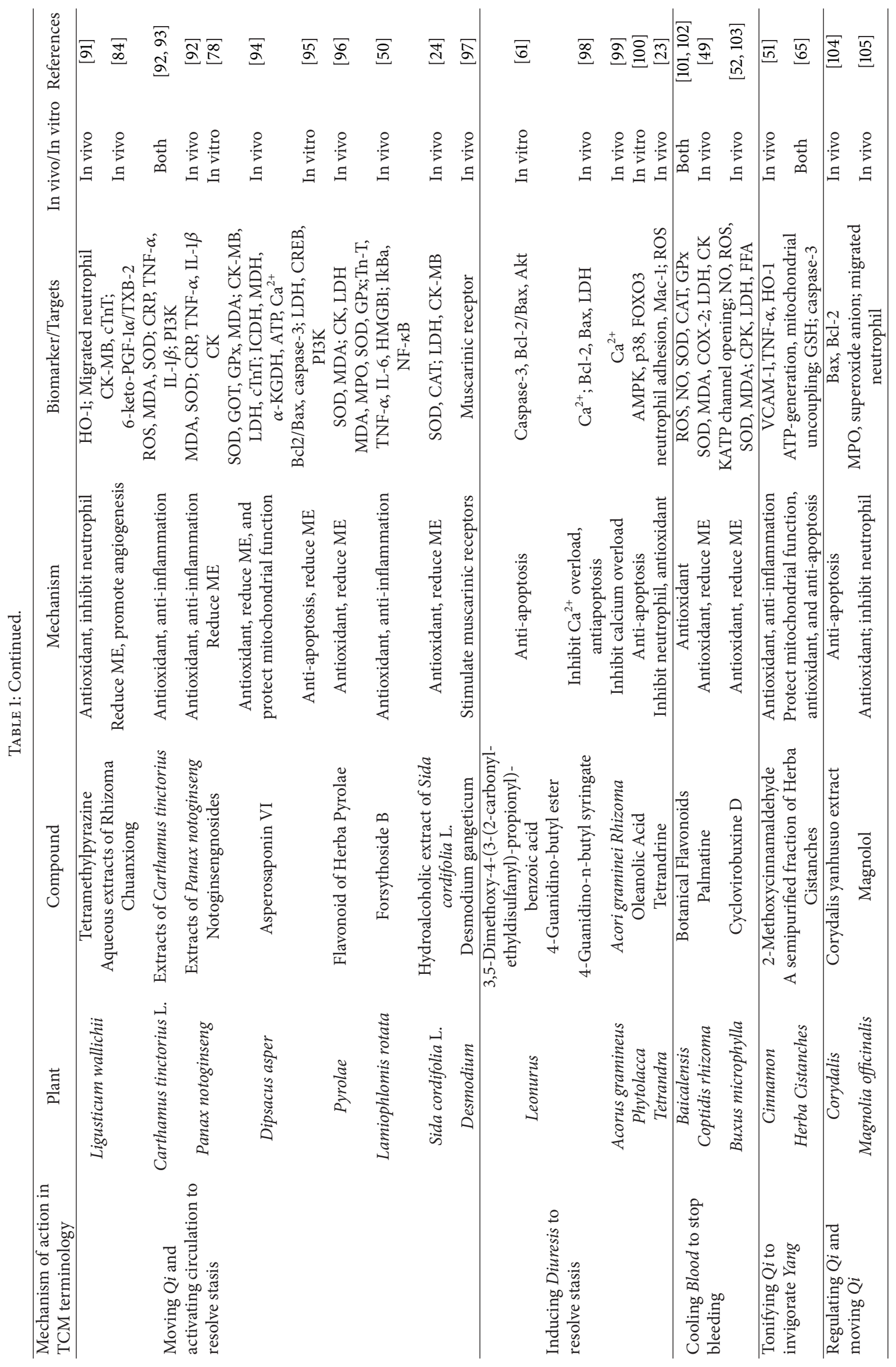


TABLE 2: Efficacy and mechanism of single Chinese herbs in the treatment of MIR.

\begin{tabular}{lccccc}
\hline $\begin{array}{l}\text { Mechanism of action in } \\
\text { TCM terminology }\end{array}$ & Herb & Mechanism & Biomarker/Targets & In vivo/In vitro References \\
\hline $\begin{array}{l}\text { Replenishing and moving } \\
\text { Qi }\end{array}$ & Rhodiola & Promote angiogenesis & VEGFR (Flt-1, KDR, and & In vivo & Tie-2) \\
& Euryale ferox (Makhana) & Antioxidant & TRP32, ROS, and Trx-1 & Both \\
Aurantii Fructus & $\begin{array}{c}\text { Recovery of contractile } \\
\text { dysfunction }\end{array}$ & $\begin{array}{c}\text { Perfusion pressure, } \\
\text { aortic flow, and coronary } \\
\text { flow }\end{array}$ & In vivo & [107] \\
\hline
\end{tabular}

in cardioprotection [57]. Shen et al. reported that neutrophils from MIR animals displayed a significant morphological change and Mac-1 up-regulation, both of which could be prevented by Tetrandrine (TTD), a compound extracted from the Chinese herb, Stephania tetrandra [23].

Decoctions and patent drugs made up of Chinese herbs have also been demonstrated to exert anti-inflammatory effects in MIR. Yin et al. showed that a significant reduction in TIMP-1 and TNF levels and improved cardiac function in MIR rats were achieved by treatment with ShuMai Decoction consisting of Astragalus mongholicus Bunge, Salvia miltiorrhiza Bge, and Eupolyphaga sinensis, in a dose-dependent manner [58]. Zhang et al. studied the patent drug Xiongshao Capsule (XSC), comprised of Chinese herbs, Rhizoma Chuanxiong and Radix Paeoniae Rubra, and found that it reduced levels of MCP-1 and TNF- $\alpha$ as well as inflammatory cell infiltration (ICI) in the ischemic myocardium [59].

3.3. Anti-Apoptosis. Alterations of pro and antiapoptotic signaling pathways, including changes in the levels of apoptosis-modulating molecules and induction of caspases, have been used to examine the anti-apoptotic effects of Chinese herbal medicine in MIR. Levels and/or activities of caspase-3, caspase-9, Bcl-2/Bax, p-JNK, p-AMPK, p-p38, phosphatidylinositol 3-kinase (PI3 K), Akt, p-I $\kappa \mathrm{B}-\alpha$, NF- $\kappa \mathrm{B}$, p65, Bcl-2-associated X protein, cytochrome $\mathrm{c}$, and forkhead transcription factor 3 (FOXO3) are among the commonly used biomarkers.

Sun et al. revealed that Salidroside and Tyrosol, two compounds extracted from the Chinese herb, Rhodiola, separately or in combination, significantly reduced caspase3 activity, cytochrome $c$ release, and JNK activation in an in vitro study [60]. Liu et al. reported that 3,5-Dimethoxy-4(3-(2-carbonyl-ethyldisulfanyl)-propionyl)-benzoic acid 4guanidino-butyl ester, derived from the Chinese herb, Leonurus, inhibited apoptosis by increasing the ratio of $\mathrm{Bcl}-2 / \mathrm{Bax}$, decreasing the level of cleaved-caspase-3, and enhancing the phosphorylation of Akt [61]. An in vivo study by Jiang et al. demonstrated that rats treated with Forsythoside B showed a significant recovery in myocardial function due to downregulated phosphorylation of IkB- $\alpha$ and NF- $\kappa \mathrm{B}$ [50].

Ling et al. studied the effects of the patent drug, Cardiotonic Pill (CP) combined with the Chinese herb, Salvia miltiorrhiza, and found that CP treatment $(50 \mathrm{mg} / \mathrm{mL})$ significantly inhibited TNF- $\alpha$-induced apoptosis in cardiomyocytes through activating Akt signaling [62]. Others have showed that Guan xin er hao (Guanxin II), which consists of the Chinese herbs, Safflower, red peony, salvia, Chuanxiong, and Dalbergiae Odoriferae, tilted the balance between Bax and $\mathrm{Bcl}-2$ toward an anti-apoptotic state, decreased mitochondrial cytochrome $\mathrm{c}$ release, reduced caspase- 9 activation, and attenuated subsequent caspase- 3 activation and postischemic myocardial apoptosis in rats $[63,64]$.

3.4. Protecting Mitochondrial Function. MPTP has been used as a target for protecting mitochondrial function by Chinese herbal medicine in the treatment of MIR. ATP-generation capacity, mitochondrial uncoupling, cAMP response element-binding protein (CREB), cytochrome $\mathrm{c}$, cytochrome P-450, mitochondrial glutathione (GSH), mitochondrial $\mathrm{Ca}^{2+}$, and mitochondrial MDA have been used as biomarkers to evaluate the effects of Chinese herbal medicine.

Wong and Ko reported that a semipurified fraction of Herba Cistanches (HCF1) increased mitochondrial ATPgeneration capacity and ADP-stimulated state respiration in $\mathrm{H} 9 \mathrm{c} 2$ cardiomyocytes during MIR. HCF1 pretreatment could protect against MIR injury in rats presumably mediated by the induction of glutathione antioxidant [65]. Siu and Ko studied the single Chinese herb, Cistanche, and found it enhanced mitochondrial glutathione status, decreased mitochondrial $\mathrm{Ca}^{2+}$ level, and increased the mitochondrial membrane potential and respiration rate in rat hearts [66]. Others reported that the patent drug, Guanxin II, decreased mitochondrial cytochrome c release and attenuated caspase- 3 activation in rat MIR myocardium $[63,64]$.

3.5. Increasing BMSCs Migration. Bone marrow mesenchymal stem cells (BMSCs) are preferentially attracted to and retained in ischemic tissue. SDF-1 and CXCR4 have been used as targets for increasing BMSC migration to protect cardiomyocytes against MIR.

Tong et al. studied the effect of Tan IIA on MIR both in vitro and in vivo. Their data showed that combination treatment with Tan IIA and BMSCs significantly reduced the infarct size and improved cardiac function after MI, which primarily resulted from Tan IIA induced increase of the migration of BMSCs to ischemic region [67].

3.6. Promoting Angiogenesis. Angiogenesis limits MIR damage by restoring tissue blood flow. Related molecules such as VEGF, von Willebrand factor (vWF), hypoxia-inducible factor $1 \alpha(\mathrm{HIF}-1 \alpha)$, VEGFR (Flt-1, KDR, and angiopoietin 


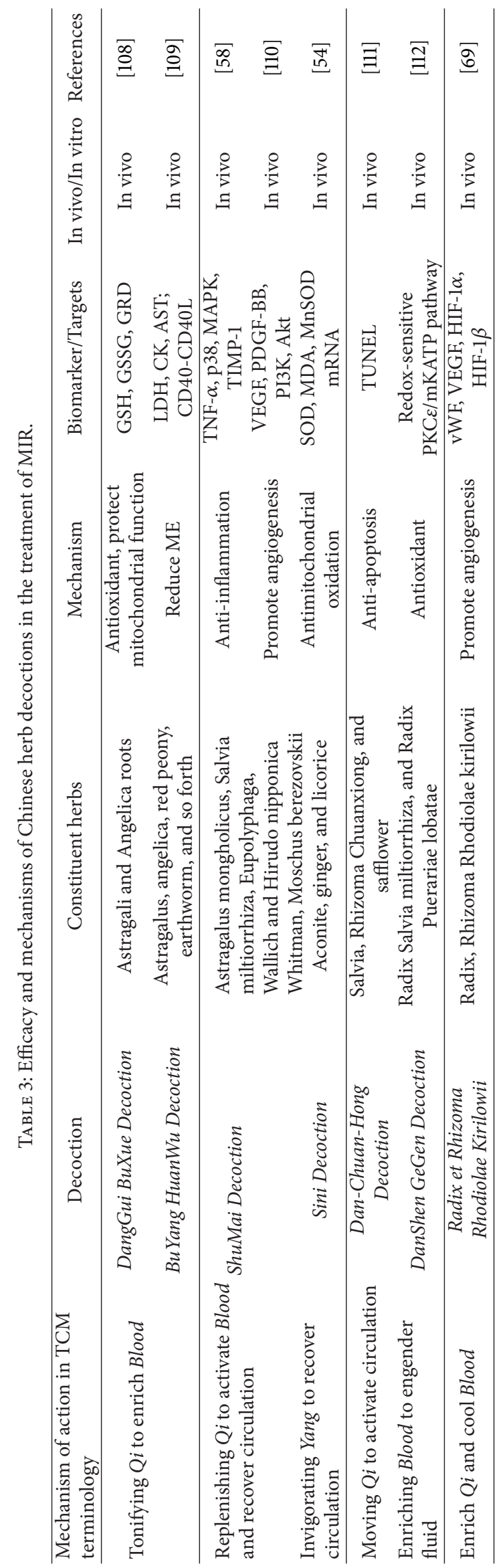




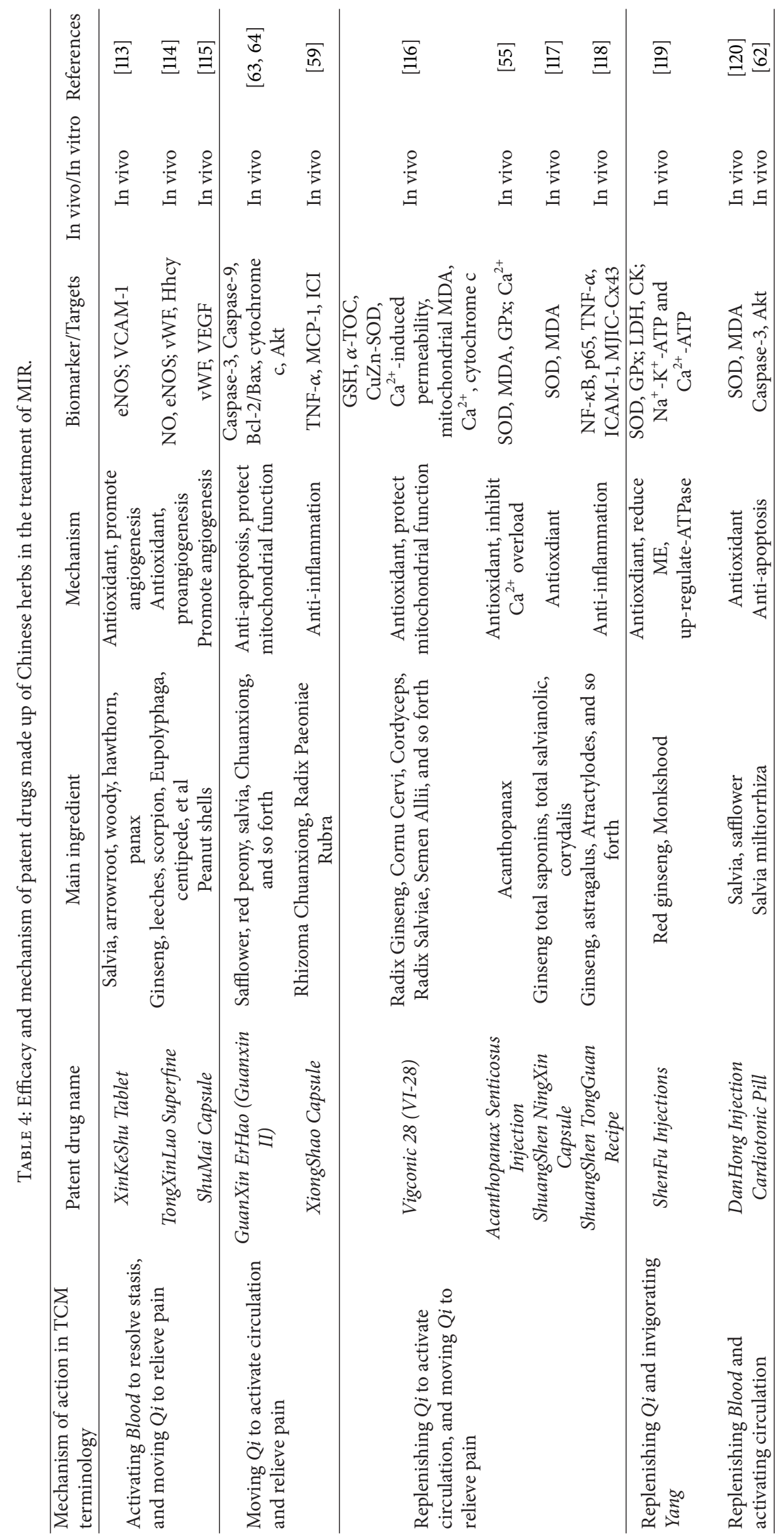


receptor (Tie-2)), platelet-derived growth factor (PDGF$\mathrm{BB}$ ), and phosphatidylinositol 3-kinase (PI3K) have been used as the targets for angiogenesis promotion to protect cardiomyocytes against MIR.

$\mathrm{Xu}$ et al. found that the compound, Tanshinone IIA, elicited a significant cardioprotective effect by up-regulating VEGF expression in MI rats and enhancing HIF- $1 \alpha$ expression [68]. Experiments of Gao et al. showed that the expressions of vWF, HIF- $1 \alpha$, HIF- $1 \beta$, and VEGF were significantly increased in myocardium treated with Radix et Rhizoma Rhodiolae Kirilowii Decoction [69].

3.7. Up-Regulating KATP Channel Subunits and ATPase, and Inhibiting Calcium Overload. KATP channel subunits Kir6.1, Kir6.2, SUR2A and SUR2B, $\mathrm{Na}^{+}-\mathrm{K}^{+}$-ATPase, $\mathrm{Ca}^{2+}$-ATPase and intracellular calcium $\left(\mathrm{Ca}^{2+}\right)$, and L-type calcium current (I-CaL) have been used to assess the effects of Chinese herbal medicine in protecting cardiomyocytes against MIR.

Han et al. examined the effects of Astragaloside IV (As IV), a compound extracted from the Chinese herb, Astragalus membranaceus. They found that As IV significantly up-regulated mRNA and protein levels of KATP channel subunits Kir6.1, Kir6.2, and SUR2A and SUR2B [70]. Lu and Zhao reported that Lycium barbarum polysaccharides, extracted from the Chinese herb, Lycium barbarum, significantly increased $\mathrm{Na}^{+}-\mathrm{K}^{+}$-ATPase and $\mathrm{Ca}^{2+}$-ATPase activities in myocardium of ischemia-reperfusion rats [71].

\section{Summary and Perspective}

In summary, significant progress has been made regarding the mechanistic research into the efficacy of Chinese herbal medicine for the treatment of MIR. However, much work remains. Most clinical studies were of limited extrapolatable value because of the small sample sizes and/or incomplete data. Experimental studies have focused mainly on single compounds extracted from Chinese herbs. Studies of Chinese decoctions or formulations are relatively scarce, although decoction and formulations are the main forms of therapy in TCM practice. Capitalization of the interactions between the different components and herbs is the essence of TCM. Many herbs are paired together to attenuate toxicity as well as to enhance efficacy. Encouragingly, the number of studies on patent Chinese herbs has been gradually increasing. These studies help us to understand the mechanisms underlying the use of Chinese herbs and formulations for the treatment of MIR. Accordingly, there is a strong likelihood that such ongoing research will lead to novel therapies for the treatment of myocardial ischemia and reperfusion injury using Chinese herbs and herbal formulations.

\begin{tabular}{|c|c|}
\hline GSH: & Glutathione \\
\hline GPx: & Glutathine peroxidease \\
\hline MPO: & Myeloperoxidase \\
\hline CAT: & Catalase \\
\hline COX-2: & Cycloxygenase- 2 \\
\hline GOT: & Glutamic oxalacetic transaminase \\
\hline ME: & Myocardial enzymes \\
\hline TRP32: & Thioredoxin-related protein-32 \\
\hline GSH: & Glutathione \\
\hline GSSG: & Oxidized glutathione \\
\hline GRD: & Glutathione reductase \\
\hline CuZn-SOD: & CuZn-superoxide dismutase \\
\hline PI3K: & Phosphatidylinositol 3-kinase \\
\hline HMGB1: & High-mobility group boxl \\
\hline HSP: & Heat shock protein \\
\hline TIMP: & $\begin{array}{l}\text { Tissue inhibitor of matrix } \\
\text { metalloproteinase }\end{array}$ \\
\hline ICI: & Inflammatory cell infiltration \\
\hline LDH: & Lactate dehydrogenase \\
\hline CK: & Creatine kinase \\
\hline CK-MB: & Creatine kinase isoenzyme-MB \\
\hline TXB2: & Thromboxane B2 \\
\hline VEGF: & Vascular endothelial growth factor \\
\hline HIF-1a: & Hypoxia-inducible factor la \\
\hline Vwf: & Von Willebrand factor \\
\hline SDF-1: & Stromal cell-derived factor-1 \\
\hline SCF-1: & Stem cell factor- 1 \\
\hline CXCR4: & CXC chemokine receptor 4 \\
\hline I-CaL: & L-type calcium current \\
\hline 15-F2t-IsoP: & 15-F2t-isoprostane \\
\hline 6-keto-PGF1-a: & 6-keto-prostaglandin Flalpha \\
\hline GR: & Glucocorticoid receptor \\
\hline CREB: & cAMP response element-binding protei \\
\hline Tn-T: & TroponinT \\
\hline FOXO3: & Forkhead transcription factor 3 \\
\hline Mac-1: & Macrophage adhesion molecule-1 \\
\hline HO-1: & Heme oxygenase-1 \\
\hline Tie-2: & Angiopoietin receptor \\
\hline TRP32: & Thioredoxin-related protein-32 \\
\hline Trx-1: & Thioredoxin-1 \\
\hline GSSG: & Oxidized glutathione \\
\hline GRD: & Glutathione reductase \\
\hline PDGF-BB: & Platelet-derived growth factor \\
\hline Hhcy: & Hyperhomocysteinemia \\
\hline MJIC-Cx43: & $\begin{array}{l}\text { Myocardial junction intercellular } \\
\text { communication connexin } 43 \text {. }\end{array}$ \\
\hline
\end{tabular}

\section{Conflict of Interests}

The authors declare that they have no conflict of interests regarding the publication of this paper.

\section{Acknowledgment}

This work was supported by Grants from the National Institute of Health nos. R21AT006767 and R01HL116626 (to D. Fan). 


\section{References}

[1] H. K. Eltzschig and T. Eckle, "Ischemia and reperfusion-from mechanism to translation," Nature Medicine, vol. 17, no. 11, pp. 1391-1401, 2011.

[2] J. L. Zweier and M. A. H. Talukder, "The role of oxidants and free radicals in reperfusion injury," Cardiovascular Research, vol. 70, no. 2, pp. 181-190, 2006.

[3] S.-F. Hsu, K.-C. Niu, C.-L. Lin, and M.-T. Lin, "Brain cooling causes attenuation of cerebral oxidative stress, systemic inflammation, activated coagulation, and tissue ischemia/injury during heatstroke," Shock, vol. 26, no. 2, pp. 210-220, 2006.

[4] I. Barut, O. R. Tarhan, N. Kapucuoglu, R. Sutcu, and Y. Akdeniz, "Lamotrigine reduces intestinal I/R injury in the rat," Shock, vol. 28, no. 2, pp. 202-206, 2007.

[5] W.-Y. Lee and S.-M. Lee, "Ischemic preconditioning protects post-ischemic oxidative damage to mitochondria in rat liver," Shock, vol. 24, no. 4, pp. 370-375, 2005.

[6] N. Vanlangenakker, T. Vanden Berghe, D. V. Krysko, N. Festjens, and P. Vandenabeele, "Molecular mechanisms and pathophysiology of necrotic cell death," Current Molecular Medicine, vol. 8, no. 3, pp. 207-220, 2008.

[7] T. V. Arumugam, P. K. Selvaraj, T. M. Woodruff, and M. P. Mattson, "Targeting ischemic brain injury with intravenous immunoglobulin," Expert Opinion on Therapeutic Targets, vol. 12, no. 1, pp. 19-29, 2008.

[8] G. Y. Chen and G. Nuñez, "Sterile inflammation: sensing and reacting to damage," Nature Reviews Immunology, vol. 10, no. 12, pp. 826-837, 2010.

[9] L. Yu, L. Wang, and S. Chen, "Endogenous toll-like receptor ligands and their biological significance," Journal of Cellular and Molecular Medicine, vol. 14, no. 11, pp. 2592-2603, 2010.

[10] D. Fan, A. Takawale, J. Lee, and Z. Kassiri, "Cardiac fibroblasts, fibrosis and extracellular matrix remodeling in heart disease," Fibrogenesis \& Tissue Repair, vol. 5, no. 1, p. 15, 2012.

[11] Y. Wang, A. M. Abarbanell, J. L. Herrmann et al., "Toll-like receptor signaling pathways and the evidence linking tolllike receptor signaling to cardiac ischemia/reperfusion injury," Shock, vol. 34, no. 6, pp. 548-557, 2010.

[12] D. J. Kaczorowski, A. Nakao, K. R. McCurry, and T. R. Billiar, "Toll-like receptors and myocardial ischemia/reperfusion, inflammation, and injury," Current Cardiology Reviews, vol. 5, no. 3, pp. 196-202, 2009.

[13] J.-I. Oyama, C. Blais Jr., X. Liu et al., "Reduced myocardial ischemia-reperfusion Injury in toll-like receptor 4-deficient mice," Circulation, vol. 109, no. 6, pp. 784-789, 2004.

[14] T. Shishido, N. Nozaki, S. Yamaguchi et al., "Toll-like receptor-2 modulates ventricular remodeling after myocardial infarction," Circulation, vol. 108, no. 23, pp. 2905-2910, 2003.

[15] J. G. Vallejo, "Role of Toll-like receptors in cardiovascular diseases," Clinical Science, vol. 121, no. 1, pp. 1-10, 2011.

[16] J. H. Boyd, S. Mathur, Y. Wang, R. M. Bateman, and K. R. Walley, "Toll-like receptor stimulation in cardiomyoctes decreases contractility and initiates an NF- $\kappa \mathrm{B}$ dependent inflammatory response," Cardiovascular Research, vol. 72, no. 3, pp. 384-393, 2006.

[17] S. K. Calderwood, S. S. Mambula, and P. J. Gray Jr., "Extracellular heat shock proteins in cell signaling and immunity," Annals of the New York Academy of Sciences, vol. 1113, pp. 28-39, 2007.

[18] S.-C. Kim, J. P. Stice, L. Chen et al., "Extracellular heat shock protein 60, cardiac myocytes, and apoptosis," Circulation Research, vol. 105, no. 12, pp. 1186-1195, 2009.
[19] I. E. Dumitriu, P. Baruah, A. A. Manfredi, M. E. Bianchi, and P. Rovere-Querini, "HMGB1: guiding immunity from within," Trends in Immunology, vol. 26, no. 7, pp. 381-387, 2005.

[20] M. Andrassy, H. C. Volz, J. C. Igwe et al., "High-mobility group box-1 in ischemia-reperfusion injury of the heart," Circulation, vol. 117, no. 25, pp. 3216-3226, 2008.

[21] P. F. Hwang, N. Porterfield, D. Pannell, T. A. Davis, and E. A. Elster, "Trauma is danger," Journal of Translational Medicine, vol. 9, no. 1, article 92, 2011.

[22] S. L. Deshmane, S. Kremlev, S. Amini, and B. E. Sawaya, "Monocyte chemoattractant protein-1 (MCP-1): an overview," Journal of Interferon and Cytokine Research, vol. 29, no. 6, pp. 313-325, 2009.

[23] Y.-C. Shen, C.-F. Chen, and Y.-J. Sung, "Tetrandrine ameliorates ischaemia-reperfusion injury of rat myocardium through inhibition of neutrophil priming and activation," British Journal of Pharmacology, vol. 128, no. 7, pp. 1593-1601, 1999.

[24] J. B. Kubavat and S. M. B. Asdaq, "Role of Sida cordifolia L. leaves on biochemical and antioxidant profile during myocardial injury," Journal of Ethnopharmacology, vol. 124, no. 1, pp. 162-165, 2009.

[25] I. R. Mohanty, U. Maheshwari, D. Joseph, and Y. Deshmukh, "Bacopa monniera protects rat heart against ischaemiareperfusion injury: role of key apoptotic regulatory proteins and enzymes," Journal of Pharmacy and Pharmacology, vol. 62, no. 9, pp. 1175-1184, 2010.

[26] P. P. Babu, G. Suzuki, Y. Ono, and Y. Yoshida, "Attenuation of ischemia and/or reperfusion injury during myocardial infarction using mild hypothermia in rats: an immunohistochemical study of Bcl-2, Bax, Bak and TUNEL," Pathology International, vol. 54, no. 12, pp. 896-903, 2004.

[27] Y. Matsui, H. Takagi, X. Qu et al., "Distinct roles of autophagy in the heart during ischemia and reperfusion: roles of AMPactivated protein kinase and beclin 1 in mediating autophagy," Circulation Research, vol. 100, no. 6, pp. 914-922, 2007.

[28] E. J. Miller, J. Li, L. Leng et al., "Macrophage migration inhibitory factor stimulates AMP-activated protein kinase in the ischaemic heart," Nature, vol. 451, no. 7178, pp. 578-582, 2008.

[29] D. Qi, X. Hu, X. Wu et al., "Cardiac macrophage migration inhibitory factor inhibits JNK pathway activation and injury during ischemia/reperfusion," Journal of Clinical Investigation, vol. 119, no. 12, pp. 3807-3816, 2009.

[30] H. Kanda and M. Miura, "Regulatory roles of JNK in programmed cell death," Journal of Biochemistry, vol. 136, no. 1, pp. $1-6,2004$.

[31] H.-M. Shen and Z.-G. Liu, "JNK signaling pathway is a key modulator in cell death mediated by reactive oxygen and nitrogen species," Free Radical Biology and Medicine, vol. 40, no. 6, pp. 928-939, 2006.

[32] N. Hanawa, M. Shinohara, B. Saberi, W. A. Gaarde, D. Han, and N. Kaplowitz, "Role of JNK translocation to mitochondria leading to inhibition of mitochondria bioenergetics in acetaminophen-induced liver injury," Journal of Biological Chemistry, vol. 283, no. 20, pp. 13565-13577, 2008.

[33] Y. Zhao and T. Herdegen, "Cerebral ischemia provokes a profound exchange of activated JNK isoforms in brain mitochondria," Molecular and Cellular Neuroscience, vol. 41, no. 2, pp. 186-195, 2009.

[34] Q. Zhou, P. Y. Lam, D. Han, and E. Cadenas, "c-Jun N-terminal kinase regulates mitochondrial bioenergetics by modulating 
pyruvate dehydrogenase activity in primary cortical neurons," Journal of Neurochemistry, vol. 104, no. 2, pp. 325-335, 2008.

[35] Q. Zhou, P. Y. Lam, D. Han, and E. Cadenas, "Activation of cJun-N-terminal kinase and decline of mitochondrial pyruvate dehydrogenase activity during brain aging," FEBS Letters, vol. 583, no. 7, pp. 1132-1140, 2009.

[36] E. P. Cummins, E. Berra, K. M. Comerford et al., "Prolyl hydroxylase- 1 negatively regulates $\mathrm{I} \kappa \mathrm{B}$ kinase- $\beta$, giving insight into hypoxia-induced NF $\mathrm{B}$ activity," Proceedings of the National Academy of Sciences of the United States of America, vol. 103, no. 48, pp. 18154-18159, 2006.

[37] T. Ha, L. Liu, J. Kelley, R. Kao, D. Williams, and C. Li, “Tolllike receptors: new players in myocardial ischemia/reperfusion injury," Antioxidants and Redox Signaling, vol. 15, no. 7, pp. 18751893, 2011.

[38] M. T. Crow, K. Mani, Y.-J. Nam, and R. N. Kitsis, "The mitochondrial death pathway and cardiac myocyte apoptosis," Circulation Research, vol. 95, no. 10, pp. 957-970, 2004.

[39] E. Murphy and C. Steenbergen, "Mechanisms underlying acute protection from cardiac ischemia-reperfusion injury," Physiological Reviews, vol. 88, no. 2, pp. 581-609, 2008.

[40] H. J. Jin, X. L. Xie, J. M. Ye, and C. G. Li, “TanshinoneIIA and cryptotanshinone protect against hypoxia-induced mitochondrial apoptosis in H9c2 cells," PloS One, vol. 8, no. 1, article e51720, 2013.

[41] G. Chamberlain, J. Fox, B. Ashton, and J. Middleton, "Concise review: Mesenchymal stem cells: their phenotype, differentiation capacity, immunological features, and potential for homing," Stem Cells, vol. 25, no. 11, pp. 2739-2749, 2007.

[42] N. Nagaya, T. Fujii, T. Iwase et al., "Intravenous administration of mesenchymal stem cells improves cardiac function in rats with acute myocardial infarction through angiogenesis and myogenesis," American Journal of Physiology-Heart and Circulatory Physiology, vol. 287, no. 6, pp. H2670-H2676, 2004.

[43] J. Hoffmann, A. J. Glassford, T. C. Doyle, R. C. Robbins, S. Schrepfer, and M. P. Pelletier, "Angiogenic effects despite limited cell survival of bone marrow-derived mesenchymal stem cells under ischemia," Thoracic and Cardiovascular Surgeon, vol. 58, no. 3, pp. 136-142, 2010.

[44] S. Kuroda, "Bone marrow stromal cell transplantation for ischemic stroke-its multi-functional feature," Acta Neurobiologiae Experimentalis, vol. 73, no. 1, pp. 57-65, 2013.

[45] R. Tabibiazar and S. G. Rockson, "Angiogenesis and the ischaemic heart," European Heart Journal, vol. 22, no. 11, pp. 903-918, 2001.

[46] S. Fukuda, S. Kaga, H. Sasaki et al., "Angiogenic signal triggered by ischemic stress induces myocardial repair in rat during chronic infarction," Journal of Molecular and Cellular Cardiology, vol. 36, no. 4, pp. 547-559, 2004.

[47] S. Ylä-Herttuala, T. T. Rissanen, I. Vajanto, and J. Hartikainen, "Vascular endothelial growth factors. Biology and current status of clinical applications in cardiovascular medicine," Journal of the American College of Cardiology, vol. 49, no. 10, pp. 1015-1026, 2007.

[48] I. Friehs, R. Barillas, N. V. Vasilyev, N. Roy, F. X. McGowan, and P. J. Del Nido, "Vascular endothelial growth factor prevents apoptosis and preserves contractile function in hypertrophied infant heart," Circulation, vol. 114, no. 1, pp. I290-I295, 2006.

[49] Y. M. Kim, Y. M. Ha, Y. C. Jin et al., "Palmatine from Coptidis rhizoma reduces ischemia-reperfusion-mediated acute myocardial injury in the rat," Food and Chemical Toxicology, vol. 47, no. 8, pp. 2097-2102, 2009.
[50] W.-L. Jiang, F.-H. Fu, B.-M. Xu, J.-W. Tian, H.-B. Zhu, and J.-H. Jian-Hou, "Cardioprotection with forsythoside B in rat myocardial ischemia-reperfusion injury: relation to inflammation response," Phytomedicine, vol. 17, no. 8-9, pp. 635-639, 2010.

[51] J. S. Hwa, Y. C. Jin, Y. S. Lee et al., "2-Methoxycinnamaldehyde from Cinnamomum cassia reduces rat myocardial ischemia and reperfusion injury in vivo due to HO-1 induction," Journal of Ethnopharmacology, vol. 139, no. 2, pp. 605-615, 2012.

[52] D. Hu, X. Liu, Y. Wang, and S. Chen, "Cyclovirobuxine D ameliorates acute myocardial ischemia by KATP channel opening, nitric oxide release and anti-thrombosis," European Journal of Pharmacology, vol. 569, no. 1-2, pp. 103-109, 2007.

[53] S. Das, P. Der, U. Raychaudhuri, N. Maulik, and D. K. Das, “The effect of Euryale ferox (makhana), an herb of aquatic origin, on myocardial ischemic reperfusion injury," Molecular and Cellular Biochemistry, vol. 289, no. 1-2, pp. 55-63, 2006.

[54] D.-Y. Zhao, M.-Q. Zhao, and W.-K. Wu, "Study on activity and mechanism of Sini Decoction anti-mitochondrial oxidation injury caused by myocardial ischemia/reperfusion," Zhong Yao Cai, vol. 31, no. 11, pp. 1681-1685, 2008.

[55] L. Wang, X.-F. Yu, S.-C. Qu, H.-L. Xu, and D.-Y. Sui, "Effects of CASI on myocardial ischemia-reperfusion arrhythmia in rats," Zhongguo Zhongyao Zazhi, vol. 32, no. 20, pp. 2174-2177, 2007.

[56] Z. H. Ren, Y. H. Tong, W. Xu, J. Ma, and Y. Chen, “Tanshinone II A attenuates inflammatory responses of rats with myocardial infarction by reducing MCP-1 expression," Phytomedicine, vol. 17, no. 3-4, pp. 212-218, 2010.

[57] P. Y. Chiu and K. M. Ko, "Schisandrin B protects myocardial ischemia-reperfusion injury partly by inducing Hsp25 and Hsp70 expression in rats," Molecular and Cellular Biochemistry, vol. 266, no. 1-2, pp. 139-144, 2004.

[58] H.-Q. Yin, B. Wang, J.-D. Zhang et al., "Effect of traditional Chinese medicine Shu-Mai-Tang on attenuating TNF $\alpha$-induced myocardial fibrosis in myocardial ischemia rats," Journal of Ethnopharmacology, vol. 118, no. 1, pp. 133-139, 2008.

[59] N. Zhang, E. R. Chen, and Y. Y. Zhang, "Effect of Guanxinkang on ATP-sensitive potassium channel in myocardial cells of rat with ischemic/ reperfusion injury," Zhongguo Zhong Xi Yi Jie He Za Zhi Zhongguo Zhongxiyi Jiehe Zazhi, vol. 30, no. 11, pp. 1186$1189,2010$.

[60] L. Sun, C. K. Isaak, Y. Zhou, J. C. Petkau, K. O. Y. Liu, and Y. L. Siow, "Salidroside and tyrosol from Rhodiola protect H9c2 cells from ischemia/reperfusion-induced apoptosis," Life Sciences, vol. 91, no. 5-6, pp. 151-158, 2012.

[61] C. Liu, W. Guo, S. Maerz, X. Gu, and Y. Zhu, “3, 5-Dimethoxy4-(3-(2-carbonyl-ethyldisulfanyl)-propionyl)-benzoic acid 4guanidino-butyl ester: a novel twin drug that prevents primary cardiac myocytes from hypoxia-induced apoptosis," European Journal of Pharmacology, vol. 700, no. 1-3, pp. 118-126, 2013.

[62] S. Ling, R. Luo, A. Dai, Z. Guo, R. Guo, and P. A. Komesaroff, "A pharmaceutical preparation of Salvia miltiorrhiza protects cardiac myocytes from tumor necrosis factor-induced apoptosis and reduces angiotensin II-stimulated collagen synthesis in fibroblasts," Phytomedicine, vol. 16, no. 1, pp. 56-64, 2009.

[63] J. Zhao, X. Huang, W. Tang et al., "Effect of oriental herbal prescription Guan-Xin-Er-Hao on coronary flow in healthy volunteers and antiapoptosis on myocardial ischemia-reperfusion in rat models," Phytotherapy Research, vol. 21, no. 10, pp. 926931, 2007. 
[64] H.-W. Zhao, F. Qin, Y.-X. Liu, X. Huang, and P. Ren, "Antiapoptotic mechanisms of Chinese medicine formula, Guan-Xin-ErHao, in the rat ischemic heart," Tohoku Journal of Experimental Medicine, vol. 216, no. 4, pp. 309-316, 2008.

[65] H. S. Wong and K. M. Ko, "Herba Cistanches stimulates cellular glutathione redox cycling by reactive oxygen species generated from mitochondrial respiration in H9c2 cardiomyocytes," Pharmaceutical Biology, vol. 51, no. 1, pp. 64-73, 2013.

[66] A. H.-L. Siu and K. M. Ko, "Herba Cistanche extract enhances mitochondrial glutathione status and respiration in rat hearts, with possible induction of uncoupling proteins," Pharmaceutical Biology, vol. 48, no. 5, pp. 512-517, 2010.

[67] Y. Tong, W. Xu, H. Han et al., "Tanshinone IIA increases recruitment of bone marrow mesenchymal stem cells to infarct region via up-regulating stromal cell-derived factor-1/CXC chemokine receptor 4 axis in a myocardial ischemia model," Phytomedicine, vol. 18, no. 6, pp. 443-450, 2011.

[68] W. Xu, J. Yang, and L.-M. Wu, "Cardioprotective effects of tanshinone IIA on myocardial ischemia injury in rats," Pharmazie, vol. 64, no. 5, pp. 332-336, 2009.

[69] X.-F. Gao, H.-M. Shi, T. Sun, and H. Ao, "Effects of Radix et Rhizoma Rhodiolae Kirilowii on expressions of von Willebrand factor, hypoxia-inducible factor 1 and vascular endothelial growth factor in myocardium of rats with acute myocardial infarction," Journal of Chinese Integrative Medicine, vol. 7, no. 5, pp. 434-440, 2009.

[70] X.-H. Han, P. Liu, Y.-Y. Zhang, N. Zhang, F.-R. Chen, and J.F. Cai, "Astragaloside IV regulates expression of ATP-sensitive potassium channel subunits after ischemia-reperfusion in rat ventricular cardiomyocytes," Journal of Traditional Chinese Medicine, vol. 31, no. 4, pp. 321-326, 2011.

[71] S. P. Lu and P. T. Zhao, "Chemical characterization of Lycium barbarum polysaccharides and their reducing myocardial injury in ischemia/reperfusion of rat heart," International Journal of Biological Macromolecules, vol. 47, no. 5, pp. 681-684, 2010.

[72] J. Fu, H. Huang, J. Liu, R. Pi, J. Chen, and P. Liu, "Tanshinone IIA protects cardiac myocytes against oxidative stress-triggered damage and apoptosis," European Journal of Pharmacology, vol. 568, no. 1-3, pp. 213-221, 2007.

[73] R. Yang, A. Liu, X. Ma, L. Li, D. Su, and J. Liu, "Sodium tanshinone IIA sulfonate protects cardiomyocytes against oxidative stress-mediated apoptosis through inhibiting JNK activation," Journal of Cardiovascular Pharmacology, vol. 51, no. 4, pp. 396401, 2008.

[74] K. K. W. Au-Yeung, O. Karmin, P. C. Choy, D.-Y. Zhu, and Y. L. Siow, "Magnesium tanshinoate B protects endothelial cells against oxidized lipoprotein-induced apoptosis," Canadian Journal of Physiology and Pharmacology, vol. 85, no. 11, pp. 10531062, 2007.

[75] B. Wang, J.-X. Liu, H.-X. Meng, and C.-R. Lin, "Blocking effect of salvianolic acid a on calcium channels in isolated rat ventricular myocytes," Chinese Journal of Integrative Medicine, vol. 18, no. 5, pp. 366-370, 2012.

[76] H.-B. He, X.-Z. Yang, M.-Q. Shi, X.-W. Zeng, L.-M. Wu, and L.-D. Li, "Comparison of cardioprotective effects of salvianolic acid B and benazepril on large myocardial infarction in rats," Pharmacological Reports, vol. 60, no. 3, pp. 369-381, 2008.

[77] R. Nie, R. Xia, X. Zhong, and Z. Xia, "Salvia miltiorrhiza treatment during early reperfusion reduced postischemic myocardial injury in the rat," Canadian Journal of Physiology and Pharmacology, vol. 85, no. 10, pp. 1012-1019, 2007.
[78] Q.-X. Yue, F.-B. Xie, X.-Y. Song et al., "Proteomic studies on protective effects of salvianolic acids, notoginsengnosides and combination of salvianolic acids and notoginsengnosides against cardiac ischemic-reperfusion injury," Journal of Ethnopharmacology, vol. 141, no. 2, pp. 659-667, 2012.

[79] X. Wang, Y. Wang, M. Jiang et al., "Differential cardioprotective effects of salvianolic acid and tanshinone on acute myocardial infarction are mediated by unique signaling pathways," Journal of Ethnopharmacology, vol. 135, no. 3, pp. 662-671, 2011.

[80] C. Pan, L. Lou, Y. Huo et al., "Salvianolic acid B and Tanshinone IIA attenuate myocardial ischemia injury in mice by no production through multiple pathways," Therapeutic Advances in Cardiovascular Disease, vol. 5, no. 2, pp. 99-111, 2011.

[81] L. Wu, H. Qiao, Y. Li, and L. Li, "Protective roles of puerarin and Danshensu on acute ischemic myocardial injury in rats," Phytomedicine, vol. 14, no. 10, pp. 652-658, 2007.

[82] R. Zhou, L.-F. He, Y.-J. Li, Y. Shen, R.-B. Chao, and J.-R. $\mathrm{Du}$, "Cardioprotective effect of water and ethanol extract of Salvia miltiorrhiza in an experimental model of myocardial infarction," Journal of Ethnopharmacology, vol. 139, no. 2, pp. 440-446, 2012.

[83] J. Sun, S. H. Huang, B. K.-H. Tan et al., "Effects of purified herbal extract of Salvia miltiorrhiza on ischemic rat myocardium after acute myocardial infarction," Life Sciences, vol. 76, no. 24, pp. 2849-2860, 2005.

[84] D.-W. Zhang, J.-G. Liu, J.-T. Feng et al., "Effects of effective components compatibility of aqueous extracts of Salviae Miltiorrhizae and Rhizoma Chuanxiong on rat myocardial ischemia/reperfusion injury," Chinese Critical Care Medicine, vol. 22, no. 2, pp. 109-112, 2010.

[85] H.-C. Wang, H. Zhang, and T.-L. Zhou, "Protective effect of hydrophilic Salvia monomer on liver ischemia/reperfusion injury induced by pro-inflammatory cytokines," Zhongguo Zhong Xi Yi Jie He Za Zhi Zhongguo Zhongxiyi Jiehe Zazhi, vol. 22, no. 3, pp. 207-210, 2002.

[86] X. Q. Yi, T. Li, J. R. Wang et al., “Total ginsenosides increase coronary perfusion flow in isolated rat hearts through activation of PI3K/Akt-eNOS signaling," Phytomedicine, vol. 17, no. 13, pp. 1006-1015, 2010.

[87] J. R. Wang, H. Zhou, X. Q. Yi, Z. H. Jiang, and L. Liu, “Total ginsenosides of Radix Ginseng modulates tricarboxylic acid cycle protein expression to enhance cardiac energy metabolism in ischemic rat heart tissues," Molecules, vol. 17, no. 11, pp. 1274612757, 2012.

[88] J.-H. Feng, Q. Shi, Y. Wang, and Y.-Y. Cheng, "Effects of Radix Ginseng and Radix Ophiopogonis extract (SMF) on protein S-nitrosylation in ischemic myocardial tissue," Zhongguo Zhongyao Zazhi, vol. 33, no. 15, pp. 1894-1897, 2008.

[89] J. Jian, F. Qing, S. Zhang, J. Huang, and R. Huang, "The effect of 17-methoxyl-7-hydroxy-benzene-furanchalcone isolated from Millettia pulchra on myocardial ischemia in vitro and in vivo," Planta Medica, vol. 78, no. 12, pp. 1324-1331, 2012.

[90] N. Chen and K. M. Ko, "Schisandrin B-induced glutathione antioxidant response and cardioprotection are mediated by reactive oxidant species production in rat hearts," Biological and Pharmaceutical Bulletin, vol. 33, no. 5, pp. 825-829, 2010.

[91] S.-Y. Chen, G. Hsiao, H.-R. Hwang, P.-Y. Cheng, and Y.-M. Lee, "Tetramethylpyrazine induces heme oxygenase-1 expression and attenuates myocardial ischemia/reperfusion injury in rats," Journal of Biomedical Science, vol. 13, no. 5, pp. 731-740, 2006.

[92] S. Y. Han, H. X. Li, X. Ma et al., "Evaluation of the antimyocardial ischemia effect of individual and combined extracts 
of Panax notoginseng and Carthamus tinctorius in rats," Journal of Ethnopharmacology, vol. 145, no. 3, pp. 722-727, 2013.

[93] S.-Y. Han, H.-X. Li, X. Ma, K. Zhang, Z.-Z. Ma, and P.-F. Tu, "Protective effects of purified safflower extract on myocardial ischemia in vivo and in vitro," Phytomedicine, vol. 16, no. 8, pp. 694-702, 2009.

[94] C. Li, Z. Liu, J. Tian et al., "Protective roles of Asperosaponin VI, a triterpene saponin isolated from Dipsacus asper Wall on acute myocardial infarction in rats," European Journal of Pharmacology, vol. 627, no. 1-3, pp. 235-241, 2010.

[95] C. Li, J. Tian, G. Li et al., "Asperosaponin VI protects cardiac myocytes from hypoxia-induced apoptosis via activation of the PI3K/Akt and CREB pathways," European Journal of Pharmacology, vol. 649, no. 1-3, pp. 100-107, 2010.

[96] C.-J. Ding, J.-T. Liu, J.-X. Wang et al., "Protective effect of total flavonoid of Herba Pyrolae on acute myocardial ischemic injury in rats," Zhong Yao Cai, vol. 30, no. 9, pp. 1105-1109, 2007.

[97] G. A. Kurian and J. Paddikkala, "Methanol extract of Desmodium gangeticum DC root mimetic post-conditioning effect in isolated perfused rat heart by stimulating muscarinic receptors," Asian Pacific Journal of Tropical Medicine, vol. 5, no. 6, pp. 448454, 2012.

[98] X.-H. Liu, P.-F. Chen, L.-L. Pan, R. D. Silva, and Y.-Z. Zhu, "4-Guanidino-n-butyl syringate (Leonurine, SCM 198) protects H9c2 rat ventricular cells from hypoxia-induced apoptosis," Journal of Cardiovascular Pharmacology, vol. 54, no. 5, pp. 437444, 2009.

[99] M. Kang, J.-H. Kim, C. Cho et al., "Effect of Acori graminei Rhizoma on contractile dysfunction of ischemic and reperfused rat heart," Biological and Pharmaceutical Bulletin, vol. 29, no. 3, pp. 483-488, 2006.

[100] J. Wang, H. Ma, X. Zhang et al., "A novel AMPK activator from Chinese herb medicine and ischemia phosphorylate the cardiac transcription factor FOXO3," International Journal of Physiology, Pathophysiology and Pharmacology, vol. 1, no. 2, pp. 116-126, 2009.

[101] E. Chan, X.-X. Liu, D.-J. Guo et al., "Extract of scutellaria baicalensis georgi root exerts protection against myocardial ischemia-reperfusion injury in rats," American Journal of Chinese Medicine, vol. 39, no. 4, pp. 693-704, 2011.

[102] C.-Z. Wang, S. R. Mehendale, T. Calway, and C.-S. Yuan, "Botanical flavonoids on coronary heart disease," American Journal of Chinese Medicine, vol. 39, no. 4, pp. 661-671, 2011.

[103] J.-Y. Zhou, H.-F. Liao, and G.-Y. Huang, "A pharmacology study of Cyclovirobuxinum D on curing myocardial ischemia induced by isoprenaline," Zhong Yao Cai, vol. 29, no. 11, pp. 12181220, 2006.

[104] H. Ling, L. Wu, and L. Li, "Corydalis yanhusuo rhizoma extract reduces infarct size and improves heart function during myocardial ischemia/reperfusion by inhibiting apoptosis in rats," Phytotherapy Research, vol. 20, no. 6, pp. 448-453, 2006.

[105] Y.-M. Lee, G. Hsiao, H.-R. Chen, Y.-C. Chen, J.-R. Sheu, and M.H. Yen, "Magnolol reduces myocardial ischemia/reperfusion injury via neutrophil inhibition in rats," European Journal of Pharmacology, vol. 422, no. 1-3, pp. 159-167, 2001.

[106] J. Li, W.-H. Fan, and H. Ao, "Effect of rhodiola on expressions of Flt-1, KDR and Tie-2 in rats with ischemic myocardium," Zhongguo Zhong Xi Yi Jie He Za Zhi Zhongguo Zhongxiyi Jiehe Zazhi, vol. 25, no. 5, pp. 445-448, 2005.

[107] M. Kang, J.-H. Kim, C. Cho et al., "Anti-ischemic effect of Aurantii Fructus on contractile dysfunction of ischemic and reperfused rat heart," Journal of Ethnopharmacology, vol. 111, no. 3, pp. 584-591, 2007.

[108] D. H. F. Mak, P. Y. Chiu, T. T. X. Dong, K. W. K. Tsim, and K. M. Ko, "Dang-Gui Buxue Tang produces a more potent cardioprotective effect than its component herb extracts and enhances glutathione status in rat heart mitochondria and erythrocytes," Phytotherapy Research, vol. 20, no. 7, pp. 561-567, 2006.

[109] Y. Liu, R. Lin, H. Zhang, J.-Y. Zhang, Q.-L. Ji, and Y.-J. Yang, "Protective effect of Buyanghuanwu Decoction on myocardial ischemia induced by isoproterenol in rats," Zhong Yao Cai, vol. 32, no. 3, pp. 380-383, 2009.

[110] H. Yin, J. Zhang, H. Lin et al., "Effect of traditional chinese medicine shu-mai-tang on angiogenesis, arteriogenesis and cardiac function in rats with myocardial ischemia," Phytotherapy Research, vol. 23, no. 1, pp. 92-98, 2009.

[111] X.-Y. Wang, F. Qin, X. Huang, X.-Y. Zhang, P. Ren, and H.-W. Zhao, "Effects of Dan-Chuan-Hong decoction on myocardial apoptosis of acute myocardial ischemia in rats," Zhong Yao Cai, vol. 32, no. 5, pp. 725-728, 2009.

[112] P. Y. Chiu, S. M. Wong, H. Y. Leung et al., "Acute treatment with Danshen-Gegen decoction protects the myocardium against ischemia/reperfusion injury via the redox-sensitive $\mathrm{PKC} \varepsilon / \mathrm{mKATP}$ pathway in rats," Phytomedicine, vol. 18, no. 11, pp. 916-925, 2011.

[113] T. Xu, J.-B. Peng, W.-T. Zhang et al., "Antiatherogenic and antiischemic properties of traditional Chinese medicine xinkeshu via endothelial protecting function," Evidence-based Complementary and Alternative Medicine, vol. 2012, Article ID 302137, 9 pages, 2012.

[114] Y.-L. Han, C. Cheng, H.-M. Tan et al., "Effect of Tongxinluo superfine on experimental anginal model (contraction of collaterals) in rat with endothelial dysfunction," Zhongguo Zhongyao Zazhi, vol. 32, no. 22, pp. 2404-2426, 2007.

[115] H.-Q. Yin, J.-D. Zhang, and H.-Q. Lin, "Experimental study on effect of Shumai capsule in promoting angiogenesis in rats with myocardial ischemia," Zhongguo Zhong Xi Yi Jie He Za Zhi Zhongguo Zhongxiyi Jiehe Zazhi, vol. 27, no. 11, pp. 1020-1022, 2007.

[116] P. Y. Chiu, H. Y. Leung, A. H. Ling Siu, N. Chen, M. K. T. Poon, and K. M. Ko, "Long-term treatment with a Yang-invigorating Chinese herbal formula produces generalized tissue protection against oxidative damage in rats," Rejuvenation Research, vol. 11, no. 1, pp. 43-62, 2008.

[117] Z. Yu, J.-X. Liu, X.-Z. Li, X.-H. Shang, A.-G. Yan, and X.-Q. Feng, "Protective effects of Shuangshen Ningxin capsule on miniature swine after myocardial ischemia by intervention," Zhongguo Zhongyao Zazhi, vol. 32, no. 16, pp. 1695-1699, 2007.

[118] J.-X. Liu, X. Han, and X.-B. Ma, "Effect of Shuangshen Tongguan Recipe on nuclear factor-kappa B signal pathway and myocardial junction-mediated intercellular communication in acute myocardial ischemia/reperfusion injured model rats," Zhongguo Zhong Xi Yi Jie He Za Zhi Zhongguo Zhongxiyi Jiehe Zazhi, vol. 25, no. 3, pp. 228-231, 2005.

[119] Z. F. Wang, "The protective of Shenfu injections on hemodynamics and myocardial enzyme after myocardial ischemia/reperfusion injury," Zhongguo Ying Yong Sheng Li Xue Za Zhi, vol. 27, no. 2, pp. 155-157, 2011.

[120] X.-J. Ma, S.-J. Yin, J.-C. Jin et al., "Synergistic protection of danhong injection and ischemic postconditioning on myocardial reperfusion injury in minipigs," Chinese Journal of Integrative Medicine, vol. 16, no. 6, pp. 531-536, 2010. 


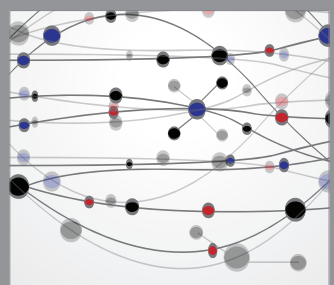

The Scientific World Journal
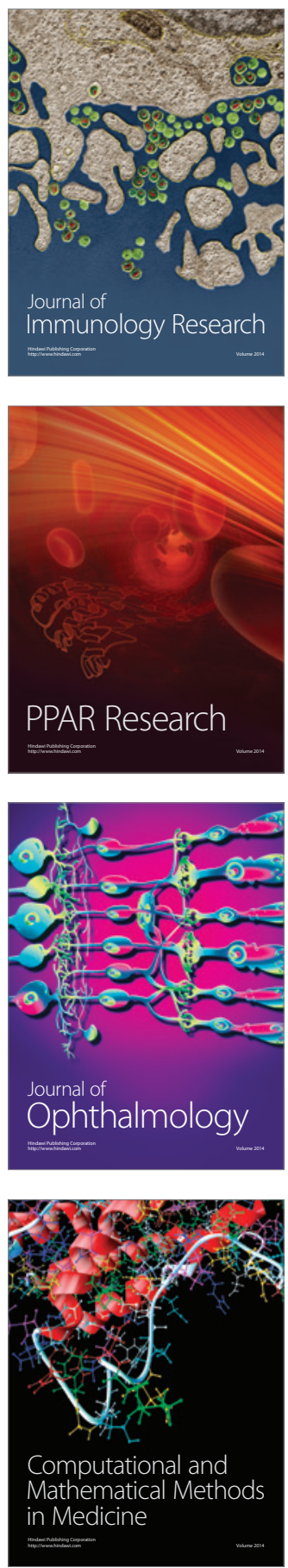

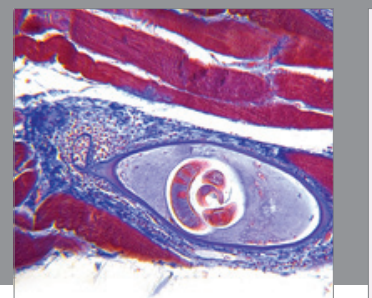

Gastroenterology

Research and Practice
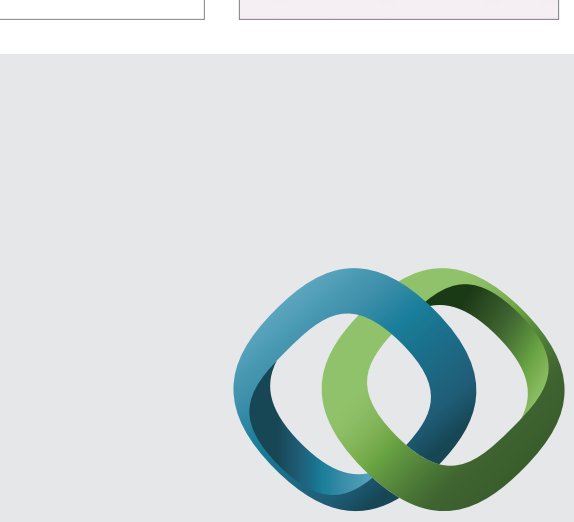

\section{Hindawi}

Submit your manuscripts at

http://www.hindawi.com
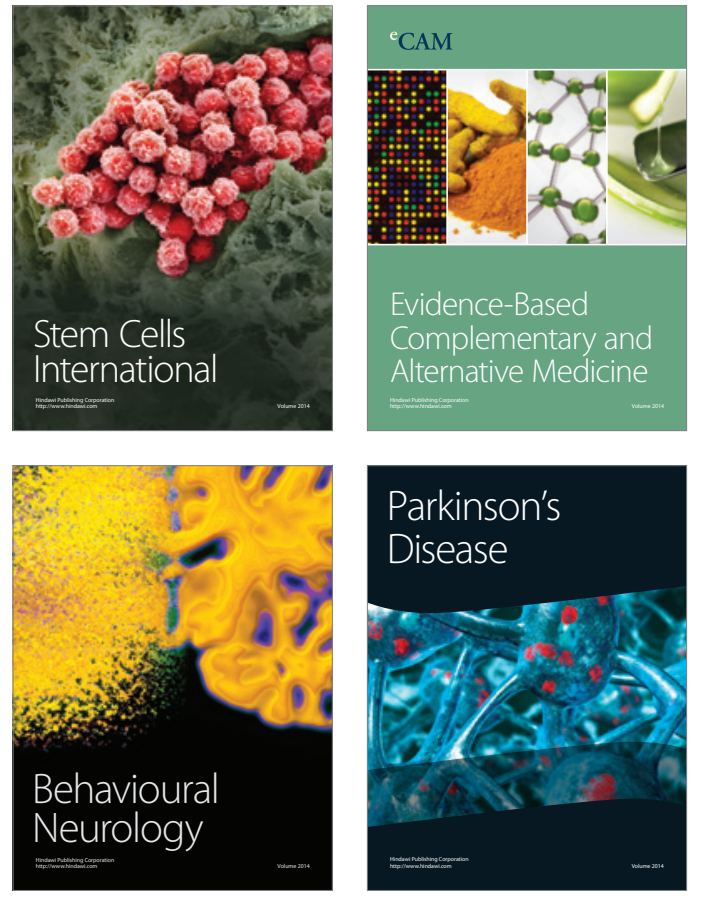
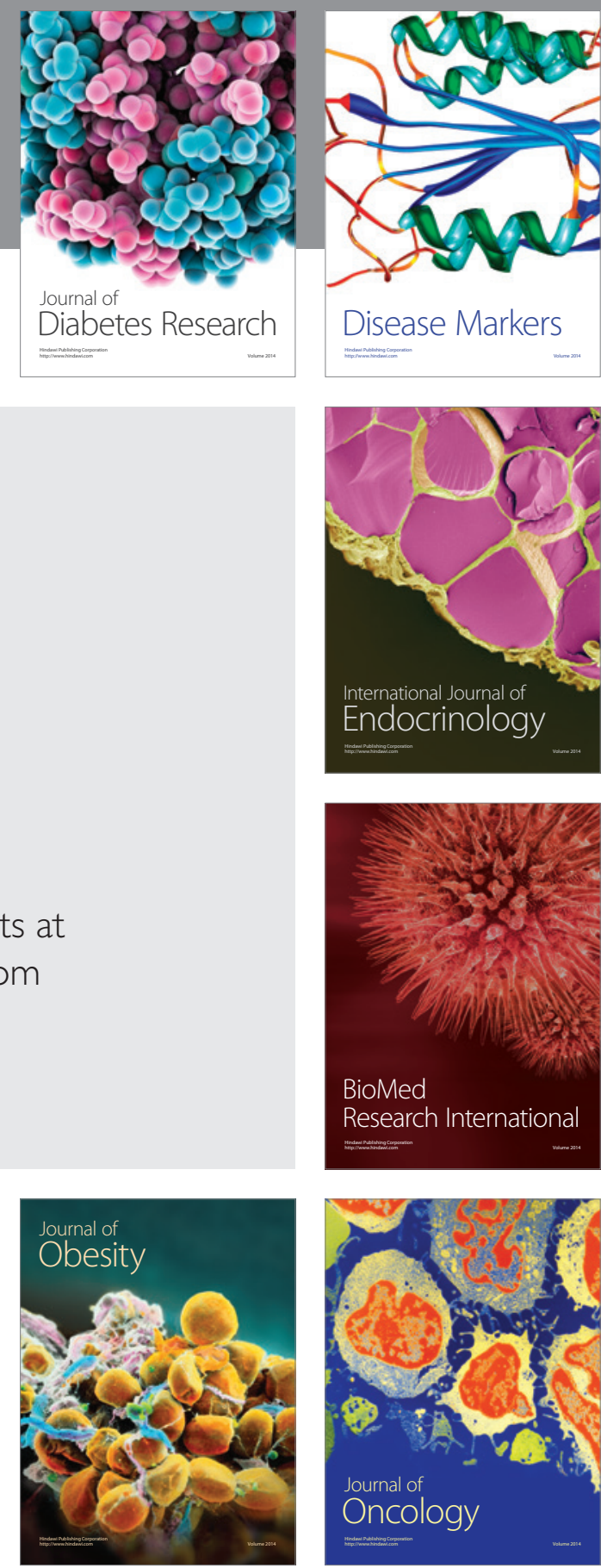

Disease Markers
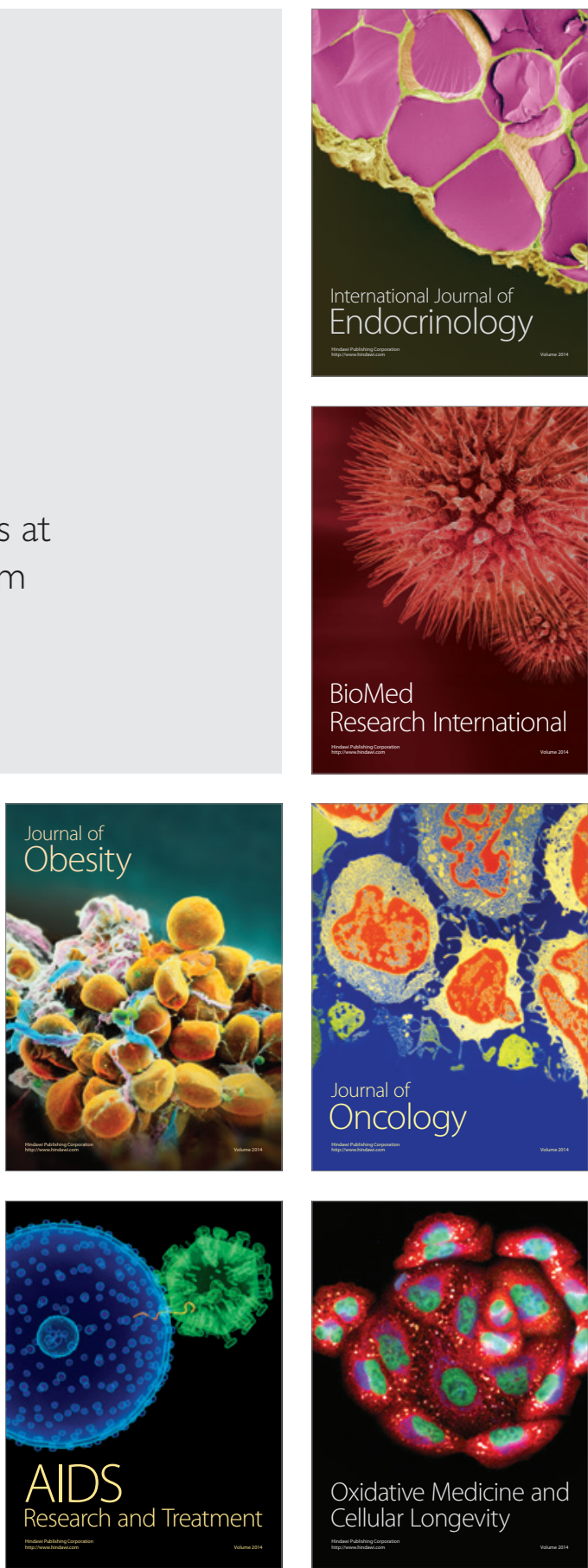